\title{
The effect of midazolam dose and age on the paradoxical midazolam reaction in Korean pediatric patients
}

\author{
Young Hee Shin, Myung Hee Kim, Jung Jin Lee, Soo Joo Choi, Mi Sook Gwak, Ae Ryoung Lee, \\ Mi Na Park, Hyo Sung Joo, and Jung Hee Choi \\ Department of Anesthesiology and Pain Medicine, Samsung Medical Center, Sungkyunkwan University School of Medicine, Seoul, Korea
}

Background: Although midazolam administration may occasionally induce a paradoxical episode, such as threatened crying and violent behavior in children, systematic studies on the causes of paradoxical reaction are limited. We investigated the effect of children's age and a dose of midazolam on the paradoxical reaction.

Methods: A total of one hundred sixty four children of 1-3 years and 3-5 years, were enrolled in this study. Each age group randomly received $0.05 \mathrm{mg} / \mathrm{kg}$ or $0.1 \mathrm{mg} / \mathrm{kg}$ of intravenous midazolam (41 patients/group).

Results: The incidence of paradoxical midazolam reaction in the study groups, 1-3 years with $0.1 \mathrm{mg} / \mathrm{kg}$ of intravenous midazolam, 1-3 years with $0.05 \mathrm{mg} / \mathrm{kg}, 3-5$ years with $0.1 \mathrm{mg} / \mathrm{kg}$, and 3-5 years with $0.05 \mathrm{mg} / \mathrm{kg}$ were as follows: 29.3\%, $12.2 \%, 7.3 \%$ and $2.4 \%$, respectively. The incidence among the 4 groups was significantly different $(\mathrm{P}=0.002)$, highest in the $1-3$ years receiving $0.1 \mathrm{mg} / \mathrm{kg}$ of midazolam $(29.3 \%)$. Both age $(\mathrm{P}=0.004, \mathrm{OR}[95 \% \mathrm{CI}]=5.3[1.7-16.8])$ and dose of midazolam $(\mathrm{P}=0.036$, OR $[95 \% \mathrm{CI}]=3.0[1.1-8.4])$ were risk factors. Perioperative clinical data including anxiety scales of children were not associated with the paradoxical midazolam reaction.

Conclusions: In conclusion, we suggest that children less than 3 years old receiving higher dose of intravenous midazolam are at risk for the paradoxical midazolam reaction. (Korean J Anesthesiol 2013; 65: 9-13)

Key Words: Child, Midazolam, Paradoxical reaction.

Received: October 19, 2012. Revised: 1st, November 20, 2012; 2nd, December 14, 2012. Accepted: December 17, 2012.

Corresponding author: Myung Hee Kim, M.D., Ph.D., Department of Anesthesiology and Pain Medicine, Samsung Medical Center, Sungkyunkwan University School of Medicine, 50, Ilwon-dong, Kangnam-gu, Seoul 135-710, Korea. Tel: 82-2-3410-2468, Fax: 82-2-3410-0361, E-mail: myungsmc@yahoo.co.kr

(c) This is an open-access article distributed under the terms of the Creative Commons Attribution Non-Commercial License (http:// creativecommons.org/licenses/by-nc/3.0/), which permits unrestricted non-commercial use, distribution, and reproduction in any medium, provided the original work is properly cited. 


\section{Introduction}

As a short acting hypnotic-sedative drug, midazolam has been used frequently in children prior to surgery to minimize preoperative anxiety and compliant induction of anesthesia. Although most pediatric patients are very positive toward the administration of midazolam, the adverse reaction has been rarely associated with midazolam administration [1-5]. These reactions are sometimes called paradoxical reactions since patients experience almost opposite effects compared with the usual sedation and anxiolysis [2]. Paradoxical reactions from the benzodiazepines typically consist of hallucinations, inconsolable crying, agitation, restlessness, disorientation, other psychological phenomena, and aggressive behavior, even needing restraint. Furthermore, children frequently do not recognize their parents. So parents are often frightened by the child's refusal of their attenpts to provide comfort [2].

The reported incidence of the paradoxical reaction varies from less than $1 \%$ to above $10 \%$, because the study protocols have not been controlled with a wide range of age $[1,2,6]$ and coadministration of other agent [2]. In addition, the cause of paradoxical midazolam reaction is unclear. In previous studies, risk factors, such as dose of midazolam [5], younger age [7], and psychological and genetic background [8] have been thought related with paradoxical reaction from benzodiazepine administration. However, the few reports on the paradoxical midazolam reaction are based on case reports $[3,8]$. There is paucity of available literature for a controlled study on the cause of midazolam-induced paradoxical reaction in pediatric patients.

Therefore, the aim of this study was to investigate whether the incidence of paradoxical reaction following intravenous midazolam is dependent on the children's age and dose of intravenous midazolam.

\section{Materials and Methods}

After obtaining our institutional ethics committee approval and written informed consent from each patient's parents/ guardian, a total of 164 American Society of Anesthesiologists physical status I-II pediatric patients, aged $1-5$ years (82 paients/1-3 years old and 82 patients/3-5 years old, respectively) undergoing elective surgeries with general anesthesia participated in this study. Additionally, to investigate the dose effect on the midazolam induced paradoxical reaction, patients of the each age group were randomly dichotomized to 2 groups to receive i.v. midazolam $0.05 \mathrm{mg} / \mathrm{kg}$ or $0.10 \mathrm{mg} /$ $\mathrm{kg}$, resulting in 4 study groups. An independent physician gave physical examinations and took histories the day before surgery in the ward. Patients who had severe hepatic, renal, cardiac, respiratory disease, physical and mental retardation, or who received drugs that might affect benzodiazepine metabolism were excluded from the current study. The levels of anxiety of children and their parents/guardian at the preoperative holding area, before the administration of midazolam, were evaluated by the subjective anesthesiologist according to the modified Yale Preoperative Anxiety Scale [9] and anxiety numerical rating scale (NRS) ranged $0-100(0=$ no anxiety, $100=$ intense anxiety ever), respectively. After placing an intravenous line at the dorsum of the hand in the ward by pediatric nurse, children were brought into the preoperative holding area (premedication section of the operating room). According to their groups, an intravenous midazolam of $0.05 \mathrm{mg} / \mathrm{kg}$ or $0.10 \mathrm{mg} / \mathrm{kg}$ (Dormicum $^{\circledR}$; Roche, Brussels, Belgium) was given to children without any notice about the injection by an anesthesiologist in charge.

Within 5 minutes following midazolam administration, abrupt unexpected behavior, such as frightened crying, restlessness, agitation or increased anxiety, aggression and rage, depression, and which is apparently different from the normal frightened reaction, was recognized as paradoxical midazolam reaction by the caring anesthesiologist. In the operating room, after placement of routine monitoring with electrocardiogram, noninvasive blood pressure and peripheral oxygen saturation, anesthesia was induced with administration of pentobarbital 5 $\mathrm{mg} / \mathrm{kg}$ intravenously under mask ventilation with oxygen and sevoflurane. After anesthetic induction, rocuronium $0.6 \mathrm{mg} /$ $\mathrm{kg}$ was followed to facilitate tracheal intubation and controlled ventilation during surgery. Anesthesia was maintained with sevoflurane in $50 \%$ oxygen during anesthesia. All patients received pethidine chloride i.v. according to body weight for pain control within $20 \mathrm{~min}$ at the end of surgery. If required, an additional opioid, such as pethidine chloride or fentanyl i.v. was administered during the stay at post anesthetic care unit (PACU). No postoperative behavioral disorder and side effects were observed in the patients during the stay in the PACU.

Prior to this study, sample size in each group was determined using power analysis. Forty patients in each group was necessary to permit at least double the incidence of paradoxical reaction in 1-3 years old children compared to that of 3-5 years old children with $0.10 \mathrm{mg} / \mathrm{kg}$ of i.v. midazolam, with a type I error of 0.05 and a power of $80 \%$ based on the estimated incidence of $10 \%$. Statistical analysis was performed using SPSS $^{\circledR}$ software (version 16.0, SPSS Inc., Chicago, IL, USA).

Demographic data, such as age, weight and height, and perioperative clinical data including fasting time, preoperative children's anxiety and parents' anxiety, operation duration, opioid dosage for immediate postoperative pain control and PACU stay were compared by using Kruskal - Wallis test or one way ANOVA among the 4 groups. Chi-sqaure test and Fisher's 
Table 1. Demographic and Perioperative Clinical Data among the Groups

\begin{tabular}{|c|c|c|c|c|c|}
\hline & $\begin{array}{c}0.10 \mathrm{mg} / \mathrm{kg} \\
1-3 \mathrm{yr}(\mathrm{n}=41)\end{array}$ & $\begin{array}{c}0.10 \mathrm{mg} / \mathrm{kg} \\
3-5 \mathrm{yr}(\mathrm{n}=41)\end{array}$ & $\begin{array}{c}0.05 \mathrm{mg} / \mathrm{kg} \\
1-3 \mathrm{yr}(\mathrm{n}=41)\end{array}$ & $\begin{array}{c}0.05 \mathrm{mg} / \mathrm{kg} \\
3-5 \mathrm{yr}(\mathrm{n}=41)\end{array}$ & $\mathrm{P}$ value \\
\hline Age (month) & $21.7 \pm 6.3$ & $46.8 \pm 7.8$ & $22.4 \pm 7.0$ & $52.7 \pm 9.4$ & $<0.001$ \\
\hline Gender $(\mathrm{M} / \mathrm{F})$ & $31 / 10$ & $28 / 13$ & $30 / 11$ & $27 / 14$ & 0.758 \\
\hline Previous operation history (n) & 14 & 14 & 13 & 17 & 0.811 \\
\hline Height $(\mathrm{cm})$ & $84.0(82.0-88.3)$ & $100.0(96.8-105.3)$ & $84.0(80.5-90.6)$ & $103.3(98.6-108.8)$ & $<0.001$ \\
\hline Weight (kg) & $11.8(10.8-13.5)$ & $16.1(14.3-17.4)$ & $11.0(10.2-12.4)$ & $17.0(15.9-18.5)$ & $<0.001$ \\
\hline Fasted time (hr) & $8.5(8.0-10.6)$ & $9.0(8.0-10.3)$ & $9.0(8.0-11.0)$ & $9.0(8.0-11.1)$ & 0.862 \\
\hline Preoperative parent anxiety (NRS) & $25.0(25.0-50.0)$ & $30.0(25.0-50.0)$ & $25.0(25.0-50.0)$ & $30.0(25.0-50.0)$ & 0.537 \\
\hline Preoperative child anxiety (mYPAS) & $50.0(25.0-50.0)$ & $41.6(25.0-50.4)$ & $33.3(25.0-50.0)$ & $36.6(25.0-50.0)$ & 0.703 \\
\hline OP duration (min) & $90.0(45.0-122.0)$ & $70.0(30.0-120.0)$ & $70.0(43.8-131.8)$ & $60.0(35.0-106.3)$ & 0.815 \\
\hline Opioid dosage (mg/kg) & $0.320 \pm 0.174$ & $0.298 \pm 0.235$ & $0.295 \pm 0.135$ & $0.355 \pm 0.207$ & 0.465 \\
\hline PACU duration (min) & $60.0(59.5-70.0)$ & $60.0(55.0-70.0)$ & $60.0(52.3-70.0)$ & $62.0(60.0-70.0)$ & 0.546 \\
\hline
\end{tabular}

Values are means \pm SD, median (IQR) or number of patients. NRS: numerical rating scale, mYPAS: modified Yale Preoperative Anxiety Scale, PACU: postanesthetic care unit.

Table 2. The Episode of Paradoxical Midazolam Reaction among the Groups

\begin{tabular}{cccccc}
\hline Paradoxical reaction & $\begin{array}{c}0.10 \mathrm{mg} / \mathrm{kg} \\
1-3 \mathrm{yr}(\mathrm{n}=41)\end{array}$ & $\begin{array}{c}0.10 \mathrm{mg} / \mathrm{kg} \\
3-5 \mathrm{yr}(\mathrm{n}=41)\end{array}$ & $\begin{array}{c}0.05 \mathrm{mg} / \mathrm{kg} \\
1-3 \mathrm{yr}(\mathrm{n}=41)\end{array}$ & $\begin{array}{c}0.05 \mathrm{mg} / \mathrm{kg} \\
3-5 \mathrm{yr}(\mathrm{n}=41)\end{array}$ & $\begin{array}{c}\text { Total } \\
\mathrm{n}=164\end{array}$ \\
\hline Yes, $\mathrm{n}(\%)$ & $12(29.3)^{*}$ & $3(7.3)$ & $5(12.2)$ & $1(2.4)$ & $21(12.8)$ \\
\hline
\end{tabular}

Values are number of patients (\%). $* \mathrm{P}<0.05$ versus $0.05 \mathrm{mg} / \mathrm{kg} / 3-5 \mathrm{yr}$ and $0.1 \mathrm{mg} / \mathrm{kg} / 3-5 \mathrm{yr}$.

Table 3. The Risk Factors of the Episode of Paradoxical Midazolam Reaction

\begin{tabular}{lll}
\hline & P value & \multicolumn{1}{c}{ OR $(95 \% \mathrm{CI})$} \\
\hline Midazolam dosage & $0.036^{*}$ & $3.015(1.076-8.443)$ \\
Age group & $0.004^{*}$ & $5.327(1.684-16.849)$ \\
\hline
\end{tabular}

*Significance based on Chi-square tests from Logistic model fitting at alpha $=0.05$. OR: odd ratio, CI: confidence interval.

exact test were used for the incidence of paradoxical reaction among the 4 groups. Logistic regression showing paradoxical midazolam reaction in the groups was performed. The OR and $95 \% \mathrm{CI}$ are presented for each group with a significant association with the incidence of paradoxical reaction. In addition, children's age and midazolam dosage as risk factors of paradoxical reaction were analyzed based on Chi-square tests from Logistic model fitting at alpha $=0.05$. Data are presented as means $\pm \mathrm{SD}$, median (IQR) or numbers (proportion). $\mathrm{P}<0.05$ was considered as significant.

\section{Results}

The demographic and perioperative clinical data among the 4 groups are shown in Table 1 . The mean age of children with midazolam of $0.05 \mathrm{mg} / \mathrm{kg}$ and $0.10 \mathrm{mg} / \mathrm{kg}$ were comparable between the groups. In perioperative clinical data, there were no significant differences among the 4 groups. In addition, the episode of paradoxical reaction was not associated with perioperative clinical data.

Of the 164 children, 143 children (87.2\%) were happy with midazolam administration and 21 children (12.8\%), aged 1-5 years, following $0.05 \mathrm{mg} / \mathrm{kg}$ or $0.10 \mathrm{mg} / \mathrm{kg}$ of i.v. midazolam as premedicant developed the episode of paradoxical reaction. When the incidence of paradoxical reaction among the 4 groups was compared, there was a significant difference $(P=0.002)$. The younger age with a higher dose of intravenous midazolam was significantly associated with paradoxical reaction. The $1-3$ years with $0.10 \mathrm{mg} / \mathrm{kg}$ of i.v. midazolam developed the paradoxical reaction in 12 children out of 41 children (29.3\%), significantly higher compared to the 3-5 years with $0.10 \mathrm{mg} / \mathrm{kg}$ of i.v. midazolam $(7.3 \%, \mathrm{P}=0.020)$ and the $3-5$ years with 0.05 $\mathrm{mg} / \mathrm{kg}$ of i.v. midazolam $(2.4 \%, \mathrm{P}=0.002)$ (Table 2$)$.

In addition, when age of children and a dose of midazolam as risk factors were assessed, the 1-3 years vs. the 3-5 years increased the incidence of paradoxical reaction 5.327 times (95\% CI [1.684-16.849]); $0.10 \mathrm{mg} / \mathrm{kg}$ of midazolam vs. $0.05 \mathrm{mg} / \mathrm{kg}$ of midazolam increased the incidence of paradoxical reaction 3.015 times (95\% CI [1.076-8.443]) (Table 3).

\section{Discussion}

This study demonstrated that the occurrence of paradoxical midazolam reaction was significantly higher $(29.3 \%)$ in the subgroup of 1-3 years $/ 0.10 \mathrm{mg} / \mathrm{kg}$ of i.v midazolam, compared to the other 3 groups. The incidence of paradoxical midazolam reaction in the 3-5 years $/ 0.10 \mathrm{mg} / \mathrm{kg}$ was $7.3 \%, 1-3$ years $/ 0.05$ 
$\mathrm{mg} / \mathrm{kg}$ was $12.2 \%$, and $3-5$ years $/ 0.05 \mathrm{mg} / \mathrm{kg}$ was $2.4 \%$. This study suggests that the ocurrence of paradoxical midazolam reaction is associated with younger children less than 3 years old receiving relatively higher dose of intravenous midazolam.

Children are highly affected by exposure to unfamiliar hospital environments and separation from parents prior to surgery. Although controversal, excessive preoperative anxiety has been suggested to be associated with postoperative behavioral changes [10]. To alleviate the fear and anxiety prior to anesthesia and surgery, midazolam premedication has been commonly used in pediatric anesthesia.

Various routes of administration of midazolam in pediatric anesthesia have been described as an effective premedication method [11]. Because most children scheduled for general anesthesia received an intravenous route in the ward prior to transferring to preopearative holding area in this institute, intravenous administration of midazolam slowly is an effective method: noninvasive, producing less irritation and maintaining a reliable plasma level. Intravenous administration of midazolam itself was successfully carried out in the current study, offering satisfaction to both children and parents in the preoperative holding area.

Although most children are happy with the administration of intravenous midazolam, unexpected paradoxical reaction such as threatened crying, aggressive behavior even needing restraint after midazolam administration can be observed by caring pediatric anesthesiologists. Once recognized for the paradoxical reaction to the midazolam administration, prompt intervention has been suggested. An additional midazolam for more sedation was not effective to alleviate patient's symptoms $[4,12]$. Accordingly, when the paradoxical reaction was recognized in this study, our pedicatric patients were immediately taken to the operating room by attending anesthesiologist and induced with sodium pentobarbital $5 \mathrm{mg} / \mathrm{kg}$ intravenously and mask ventilation with sevoflurane in $100 \%$ oxygen. All patients including children having paradoxical reactions underwent anesthetic induction successfully without any vital problems in the current study.

We selected children, aged 1-5 years, in this study because most infants less than 12 months do not need anxiolysis in general, and children above school ages can understand their current situation and can make rapport with medical staff including pediatric anesthesiologist. It is difficult to discern the incidence of paradoxical midazolam reaction in children by literature review, because of the wide range of studied children's age $[1,2,6]$ and coadministration of other agents [2]. No one paradoxical reaction in a study published in Austria has been observed with $0.10 \mathrm{mg} / \mathrm{kg}$ of i.v. midazolam in 500 infants and children up to 19 years, undergoing propofol based sedation regimen for magnetic resonance imaging [6]. Massanari et al. [2] observed that $1.4 \%$ of 2,617 children, ages $1-17$ years, who received intravenous midazolam and meperidine for endoscopic procedures performed in USA, developed an episode of paradoxical reaction. In a recent study with 706 Iran children, aged 6 months -6 years, similar to the children's age of this study, $3.4 \%$ deveolped paradoxical reaction following $0.1 \mathrm{mg} / \mathrm{kg}$ of intravenous midazolam as premedicant prior to elective surgery [4]. However, when we subdivided the subject children, aged 1-5 years, into the 1-3 years and the 3-5 years, our findings lead us to suggest that age less than 3 years old is a significant risk factor compared to the 3-5 years in the occurrence of the paradoxical midazolam reaction. As predicted, a relatively higher dose of intravenous midazolam compared to low dose was also a risk factor in this study. It is interesting to note that paradoxical reaction was not significantly noticeable in the in the 3-5 years with $0.05 \mathrm{mg} / \mathrm{kg}$ of intravenous midazolam (2.4\%). Supporting this study, a previous study with diazepam demonstrated that adverse reaction to diazepam was more frequent in younger age and the incidence was reduced as age increased [7]. Roelofse et al.[5] suggested that the incidence of paradoxical midazolam reaction following rectal midazolam administration was strongly dependent on dosages. Although paradoxical midazolam reaction is believed to be idiosyncratic, administered midazolam amount [5], age of children, underlying emotional and psychiatric disorder [13], genetic basis [8] have been suggested as the related factors at increased risk. Assessing the relationship with clinical conditions against ocurrence of paradoxical reaction, and contrary to the result by Golparvar et al. [4], we did not find any association of the episode of paradoxical phenomenon with previous surgical history, fasting time, preoperative anxiety score of the subjected children and their parents/guardian at preoperative holding area, and delayed resume of ventilation at the end of surgery in the current study. As limitations of this study we were unable to assess the basal characteristic of children. Finley et al. [14] recommended that if the basal characteristic of children is a highly impulsive trait, midazolam premedication should not be advised as premedicant. As another limitation, there was not enough sample size to pursue multivariate analysis for many other independent variables apart from age and midazolam dosages.

In conclusion, we suggest that the younger less than 3 years old receiving higher dose of intravenous midazolam are at risk for the paradoxical midazolam reaction. 


\section{References}

1. Uldum B, Hallonsten AL, Poulsen S. Midazolam conscious sedation in a large Danish municipal dental service for children and adolescents. Int J Paediatr Dent 2008; 18: 256-61.

2. Massanari M, Novitsky J, Reinstein LJ. Paradoxical reactions in children associated with midazolam use during endoscopy. Clin Pediatr (Phila) 1997; 36: 681-4.

3. Robin C, Trieger N. Paradoxical reactions to benzodiazepines in intravenous sedation: a report of 2 cases and review of the literature. Anesth Prog 2002; 49: 128-32.

4. Golparvar M, Saghaei M, Sajedi P, Razavi SS. Paradoxical reaction following intravenous midazolam premedication in pediatric patients - a randomized placebo controlled trial of ketamine for rapid tranquilization. Paediatr Anaesth 2004; 14: 924-30.

5. Roelofse JA, Stegmann DH, Hartshorne J, Joubert JJ. Paradoxical reactions to rectal midazolam as premedication in children. Int J Oral Maxillofac Surg 1990; 19: 2-6.

6. Machata AM, Willschke H, Kabon B, Kettner SC, Marhofer P. Propofol-based sedation regimen for infants and children undergoing ambulatory magnetic resonance imaging. Br J Anaesth 2008; 101: 239-43.

7. Litchfield NB. Complications of Intravenous Diazepam - Adverse Psychological Reactions. (An assessment of 16,000 cases). Anesth Prog 1980; 27: 175-83.

8. Short TG, Forrest P, Galletly DC. Paradoxical reactions to benzodiazepines--a genetically determined phenomenon? Anaesth Intensive Care 1987; 15: 330-1.

9. Kain ZN, Mayes LC, Cicchetti DV, Bagnall AL, Finley JD, Hofstadter MB. The Yale Preoperative Anxiety Scale: how does it compare with a "gold standard"? Anesth Analg 1997; 85: 783-8.

10. Kain ZN, Mayes LC, O'Connor TZ, Cicchetti DV. Preoperative anxiety in children. Predictors and outcomes. Arch Pediatr Adolesc Med 1996; 150: 1238-45.

11. Kogan A, Katz J, Efrat R, Eidelman LA. Premedication with midazolam in young children: a comparison of four routes of administration. Paediatr Anaesth 2002; 12: 685-9.

12. Thurston TA, Williams CG, Foshee SL. Reversal of a paradoxical reaction to midazolam with flumazenil. Anesth Analg 1996; 83: 192.

13. Honan VJ. Paradoxical reaction to midazolam and control with flumazenil. Gastrointest Endosc 1994; 40: 86-8.

14. Finley GA, Stewart SH, Buffett-Jerrott S, Wright KD, Millington D. High levels of impulsivity may contraindicate midazolam premedication in children. Can J Anaesth 2006; 53: 73-8. 